\title{
Correction: Evaluation of medical and surgical decompression in patients with dysthyroid optic neuropathy
}

Aylin Garip Kuebler (D) - Caroline Wiecha - Lukas Reznicek • Annemarie Klingenstein • Kathrin Halfter (DD Siegfried Priglinger - Christoph Hintschich

Published online: 20 May 2020

(c) The Author(s), under exclusive licence to The Royal College of Ophthalmologists 2020

Correction to: Eye

https://doi.org/10.1038/s41433-020-0897-x
In the original article, one of the authors (Dr Annemarie Klingenstein) was not included in the author list. This has been corrected in the PDF, HTML and XML versions of this article. 